\title{
ASPECTS REGARDING THE EFFECTIVENESS OF VOLATILE OILS OF THE TANACETUM VULGARE KIND IN THE CONSERVATION OF HERITAGE OBJECTS
}

\author{
LUCRETIA MIU ${ }^{1}$, RODICA-ROXANA CONSTANTINESCU ${ }^{1}$, ALPASLAN DURMUŞ \\ KAYA $^{2}$, EMANUEL HADIMBU ${ }^{1}$, CLAUDIU ȘENDREA ${ }^{1}$, MARIA-CRISTINA MICU, \\ SIMONA-MARIA PĂUNESCU ${ }^{1}$, IULIA MARIA CANIOLA ${ }^{1}$, ELENA BADEA ${ }^{1,3^{*}}$ \\ ${ }^{1}$ INCDTP - Division Leather and Footwear Research Institute, Bucharest, Romania \\ ${ }^{2}$ Hatay Mustafa Kemal University, Faculty of Agriculture, Field Crops Department, 31034, \\ Antakya-Hatay, Turkey \\ ${ }^{3}$ Department of Chemistry, Faculty of Sciences, University of Craiova, Craiova, Romania, \\ elena.badea@unito.it
}

\begin{abstract}
The paper refers to a composition with antifungal and antibacterial effect in order to test new materials for preserving heritage objects on collagen support with bactericidal/antifungal role, essential oils-based from Vetrice (Tanacetum vulgare, Compositae family), having antifungal and antibacterial properties. The biocidal effect of plant extracts is due to the presence of constituent agents, such as alcohols, ethers, phenols, aldehydes, ketones, which makes them extremely effective against a wide range of microbial strains. The essential oil was obtained by boiling the plants through continuous hydrodistillation with Clevenger refrigerant. The testing of the antimicrobial efficiency of the plant extracts was performed on two strains of pathogenic fungi, respectively Trichophyton interdigitale and Epidermophyton floccosum. The microbial inoculum was mixed with the plant extract from various sources (leaves, flowers and mixed flower-leaves). All extracts were tested in duplicate according to the specific test standards, and the results were expressed as a mean percentage and logarithmic reduction between the readings on the two Petri plates corresponding to each sample. To quantify the antimicrobial efficacy, the degree of microbial and logarithmic reduction of each sample was calculated, relative to the initial cell concentration. The results of antimicrobial tests showed a high antifungal character of the extracts obtained from flowers, leaves and mixed flower-leaves.
\end{abstract}

Keywords: preserving heritage objects, antifungal and antibacterial effect

\section{INTRODUCTION}

The paper refers to a study on the antifungal and antibacterial effect of Tanacetum vulgare essential oil in the curative and preventive conservation of heritage objects on collagen support.

Animal hide, but also tanned leather, due to its structure and chemical composition, which includes a large amount of proteins (collagen, elastin, albumin), mucopolysaccharides, water, fat and mineral salts is an excellent culture medium for the development of biological factors-microorganisms (bacteria, molds), which damage both the surface and the structure of the skin.

Since ancient times, essential oils have been widely used for bactericidal, fungicidal, insecticidal, medicinal and cosmetic applications. They are currently used in the pharmaceutical, sanitary, cosmetic, agricultural and food industries. Plant-derived essential oils have great potential as antimicrobial agents against a wide range of pathogens. The biocidal effect of plant extracts is due to the presence of constituent agents, such as alcohols, ethers, phenols, aldehydes, ketones, which makes them extremely effective against a wide range of microbial strains. Fast and sensitive detection of dermatophytes is very helpful because most superficial fungal infections are caused by this group of fungi (Kupsch et al., 2016; Garg et al., 2009). Their exact 
identification is essential for choosing the most appropriate antimicrobial treatment and for tracking the sources of infection, thus helping to avoid reinfection (Jung et al., 2009).

Various emollient and conservation compositions based on lanolin, hoof oil, beeswax and hexane are known, with cedar oil as an antifungal preservative [British Museum dressing]. Research is also known on the use of lavender oil to preserve and protect the atmosphere in archives and libraries that are effective against insects and molds. It is known that in libraries and warehouses, collagen-based objects are subject to the attack of mold and bacteria due to variable temperature conditions, degradation of skin structure, changes in acidity.

Tanacetum vulgare (family Asteraceae), popularly called Vetrice is a species native to Europe (up to one meter tall, strong chrysanthemum-like scent, specific, dark green, with beautiful intense yellow flowers), but widespread also in the spontaneous flora of Asia and North America. This plant has been known since ancient times as a therapeutic remedy, being cultivated in gardens, having uses in medicine (antibacterial, antiseptic, anti-inflammatory) but also in cosmetics, food (spice), obtaining perfumes, insecticides, preservatives, all these properties being obtained due to its composition rich in bioactive components such as polyphenols, flavonoids and tannins. The basic chemical composition of the volatile oil from Tanacetum vulgare is complex, depending on the morpho-anatomical part of the plant (leaves or flowers; the stem has no volatile oils), climate (temperature, amount of precipitation) of soil, altitude, etc. For the extraction process, the plant was separated into flowers and leaves, the extractions being performed separately for each of them with the help of a Clevenger extractor. There are numerous studies on the composition of essential oils extracted from Tanacetum vulgare and which highlight the potential of their use especially in medicine, pharmacy and cosmetics (Muresan, 2015; Boucher et al., 2017; Kumar et al., 2016; Ulukanli et al., 2017; Marian et al., 2013).

The effectiveness of the active principles extracted Tanacetum vulgare has been studied on Epidermophyton and Trichophyton which are fungi that cause skin diseases in animals and humans. Conventional methods for identifying these fungi are quick and simple, but they are qualitatively comparable to molecular methods (Grumbt et al., 2013). Both strains were selected due to their enzymatic structure.

Trichophyton interdigitale is an anthropophilic fungus that is a common cause of tinea pedis, especially vesicular type, tinea corporis, and sometimes superficial nail invasion. Trichophyton interdigitale is also responsible for the condition called "athlete's foot" that affects the skin between the toes (Wisselink et al., 2011).

Epidermophyton floccosum is an anthropophilic dermatophyte with a worldwide distribution and one of the most common causes of dermatophytosis in healthy individuals. It infects the skin (tinea corporis, tinea cruris, tinea pedis) and nails (onychomycosis). Infection is limited to the stratum corneum of the epidermis because the microorganism does not have the ability to penetrate viable tissues of the immunocompetent host (Gueho et al., 2015).

The use of conservation products aims to lubricate the fibers of tanned leather, with a role in reducing fragility and the tendency to break, preventing them from sticking to repeated drying. The products offer softness, suppleness and reduce water absorption. The role of the products used in the conservation of heritage leather is to surround the fibrillar elements of the tanned leather, so as to give it the softness and elasticity 
necessary for a proper use, and also to offer protection in case of fungicidal and bactericidal attacks.

\title{
EXPERIMENTAL PART
}

\begin{abstract}
Materials
In order to test new materials for the conservation of heritage objects on collagenic support with bactericidal / antifungal role, essential oils were obtained from Vetrice (Tanacetum vulgare, fam. Compositae), a perennial plant that sows itself, having antifungal and antibacterial properties. The chopped plant, which can be dried or green, has been extracted in a Clevenger refrigerant. Essential oils are mixtures of 5, 10 to tens and even a hundred compounds. In an essential oil each compound has specific biological properties and participates in the overall harmonization of the odor and specific activity (antimicrobial, antifungal, regenerative, antibacterial) of the mixture. Extracts of essential oils with various origins were tested, as follows: Flower extract, with F notations; Leaf extract, with L notations; Mixed flower and leaf extract, with $\mathrm{M}$ notations. Each extract was tested in 2 concentrations, the dilutions being made in paraffin oil, respectively: $1 \%$ and $3 \%$;
\end{abstract}

\section{Method}

Testing of the extracts was performed in a 1: 1 ratio with the microbial inoculum, for a final solution volume of $1 \mathrm{~mL}(500 \mu \mathrm{L}$ extract as such or diluted $+500 \mu \mathrm{L}$ microbial inoculum). Fresh cultures were obtained from each strain, by growing in nutritious Czapek-Dox broth, at $28{ }^{\circ} \mathrm{C}$ for 14 days, representing the stock culture. For testing, two decimal dilutions in paraffin oil $\left(10^{-2}\right)$ were made from each culture and the cell concentration in the inoculum used was $9.8 \times 10^{3} \mathrm{UFC} / \mathrm{mL}$ (Colony Forming Units) for Trichophyton interdigitale (with $\mathrm{Ti}$ notations). and $8.92 \times 10^{3} \mathrm{UFC} / \mathrm{mL}$ for Epidermophyton floccosum (with Ef notations).

The initial cell concentration was previously determined by decimal dilutions $\left(10^{-4}\right)$ in sterile deionized water, and from the last dilution, for each strain, $100 \mu \mathrm{L}$ were taken and spread on Czapek-Dox agarized nutrient medium. The counts on the plate were performed after $24 \mathrm{~h}$ of incubation, these being kept as a reference for the cellular developments in the control sample from the sample set (taken as the sample performed in paraffin oil). Thus, plates with cell density similar to that of dilution $10^{-4}$ were considered to have similar UFC values $\left(9.8 \times 10^{3} \mathrm{UFC} / \mathrm{mL}\right.$-Trichophyton interdigitale and $8.92 \times 10^{3}$ UFC / mL-Epidermophyton floccosum). This method was chosen due to the very low dilution $\left(10^{-2}\right)$ performed in the case of the inoculum that was tested on extracts, respectively of a high cellular concentration, which makes it extremely difficult to count filamentous fungal colonies in plates with abundant development.

The experiments on extracts were performed in Eppendorf tubes, previously sterilized at $121{ }^{\circ} \mathrm{C}$, for $15 \mathrm{~min}$. The extracts were not sterilized, in order to avoid the volatilization of their active principles. The microbial inoculum was mixed with the plant extract, from various origins (flowers, leaves and mixed flower leaves), both the microbial inoculum and the extract having constant volumes $(500 \mu \mathrm{L})$, only the concentration of extract and paraffin oil varying in these $500 \mu \mathrm{L}$. The microbial inoculum solution was prepared in paraffin oil to rule out its possible antimicrobial activity on microbial cells. 


\section{RESULTS AND DISCUSSIONS}

All extracts were tested in duplicate according to the specific test standards, and the results were expressed as a mean percentage and logarithmic reduction between the readings on the two Petri plates corresponding to each sample. Plate counts were performed after $24 \mathrm{~h}$ incubation to detect colony-forming cell units. Pictures of the Petri dishes were taken after $48 \mathrm{~h}$ incubation. To quantify the antimicrobial efficacy, the degree of microbial and logarithmic reduction of each sample was calculated, relative to the initial cell concentration (Table 1).

Table 1. Antifungal test results

\begin{tabular}{|c|c|c|c|c|c|}
\hline Sample & Petri Image & Mean 2 plates & $* \mathrm{R} \%$ & $* * \log _{10}$ red. & Source \\
\hline \multicolumn{6}{|c|}{ Trichophyton interdigitale } \\
\hline M & & $\begin{array}{c}(9800+9800) / 2 \\
\mathrm{M}=9800 \text { colonies } \\
=> \\
9,8 \times 10^{3} \mathrm{UFC} / \mathrm{mL}\end{array}$ & - & - & $\begin{array}{c}\text { Untreated } \\
\text { Sample }\end{array}$ \\
\hline 1 & & $\begin{array}{c}(13+13) / 2 \\
\mathrm{M}=130 \text { colonies } \\
=> \\
13 \times 10^{1} \mathrm{UFC} / \mathrm{mL}\end{array}$ & 95,55 & 1,88 & $1 \% \mathrm{FTi}$ \\
\hline 2 & & $\begin{array}{c}(14+14) / 2 \\
\mathrm{M}=140 \text { colonies } \\
=> \\
14 \times 10^{1} \mathrm{UFC} / \mathrm{mL}\end{array}$ & 95,5 & 1,85 & $1 \% L T i$ \\
\hline 3 & & $\begin{array}{c}(19+20) / 2 \\
\mathrm{M}=1950 \text { colonies } \\
=> \\
19,5 \times 10^{3} \mathrm{UFC} / \mathrm{mL}\end{array}$ & 92,3 & 1,7 & $1 \% M T i$ \\
\hline 4 & & $\begin{array}{c}(3+4) / 2 \\
\mathrm{M}=35 \text { colonies }=> \\
3,5 \times 10^{1} \mathrm{UFC} / \mathrm{mL}\end{array}$ & 99,65 & 1,45 & $3 \% \mathrm{FTi}$ \\
\hline 5 & & $\begin{array}{c}(0+1) / 2 \\
\mathrm{M}=5 \text { colonii } \\
=> \\
5 \mathrm{UFC} / \mathrm{mL}\end{array}$ & 100 & 3,26 & $3 \% L T i$ \\
\hline 6 & & $\begin{array}{c}(1+1) / 2 \\
\mathrm{M}=10 \text { colonies } \\
\Rightarrow \\
1 \times 10^{1} \mathrm{UFC} / \mathrm{mL}\end{array}$ & 99,9 & 2,99 & $3 \% M T i$ \\
\hline
\end{tabular}


ICAMS $2020-8^{\text {th }}$ International Conference on Advanced Materials and Systems

\begin{tabular}{|c|c|c|c|c|c|}
\hline Sample & Petri Image & Mean 2 plates & $* \mathrm{R} \%$ & *** $\log _{10}$ red. & Source \\
\hline \multicolumn{6}{|c|}{ Epidermophyton floccosum } \\
\hline M & & $\begin{array}{c}(8920+8920) / 2 \\
\mathrm{M}=8920 \text { colonies } \\
\Rightarrow> \\
8,92 \times 10^{3} \mathrm{UFC} / \mathrm{mL}\end{array}$ & & & $\begin{array}{c}\text { Untreated } \\
\text { Sample }\end{array}$ \\
\hline 7 & & $\begin{array}{c}(1+1) / 2 \\
\mathrm{M}=10 \text { colonies }=> \\
1 \times 10^{1} \mathrm{UFC} / \mathrm{mL}\end{array}$ & 99,9 & 2.95 & $1 \% \mathrm{FEf}$ \\
\hline 8 & & $\begin{array}{c}(12+14) / 2 \\
\mathrm{M}=130 \text { colonies }=> \\
13 \times 10^{2} \mathrm{UFC} / \mathrm{mL}\end{array}$ & 95,5 & 1,84 & $1 \% L E f$ \\
\hline 9 & & $\begin{array}{c}(14+16) / 2 \\
\mathrm{M}=\text { colonies } \Rightarrow \\
15 \times 10^{2} \mathrm{UFC} / \mathrm{mL}\end{array}$ & 95,55 & 1,78 & $1 \% M E f$ \\
\hline 10 & & $\begin{array}{c}(2+2) / 2 \\
\mathrm{M}=2 \text { colonies }=> \\
2 \times 10^{1} \mathrm{UFC} / \mathrm{mL}\end{array}$ & 99,77 & 2.65 & $3 \%$ FEf \\
\hline 11 & & $\begin{array}{c}(1+1) / 2 \\
\mathrm{M}=10 \text { colonies } \\
\Rightarrow> \\
1 \times 10^{1} \mathrm{UFC} / \mathrm{mL}\end{array}$ & 99,9 & 2,95 & $3 \%$ LEf \\
\hline 12 & $*$ & $\begin{array}{c}(8+9) / 2 \\
\mathrm{M}=125 \text { colonies }=> \\
12,5 \times 10^{1} \mathrm{UFC} / \mathrm{mL}\end{array}$ & 99,85 & 1,86 & $3 \% M E f$ \\
\hline
\end{tabular}

* Antibacterial activity ratio $(R) \quad R=\frac{C_{\mathrm{t}}-T_{\mathrm{t}}}{C_{\mathrm{t}}} X 100 \% ; C_{t}=$ is the average number of colonies of two control samples after $24 \mathrm{~h}$ or the specified incubation period, expressed as CFU/ml; $T_{t}=$ is the average number of colonies of two test samples after $24 \mathrm{~h}$ or the specified incubation period, expressed as CFU/ml. The percentage reduction can be interpreted in logarithmic reduction, as follows: $90 \%$ reduction $=1 \log$ reduction $(1,000,000$ cells reduced to 100,000 represents $1 \log$ reduction); $99 \%$ reduction $=2 \log$ reduction $(1,000,000$ cells reduced to 10,000 represents $2 \log$ reduction); $99.9 \%$ reduction $=3 \log$ reduction $(1,000,000$ cells reduced to 1000 represents $3 \log$ reduction); $99.99 \%$ reduction $=4 \log$ reduction $(1,000,000$ cells reduced to 100 represents $4 \log$ reduction)

** Antibacterial activity value (A), $A=\lg C_{\mathrm{t}}-\lg T_{\mathrm{t}} \quad$ where $A$ - is the antibacterial activity value; $\lg C_{\mathrm{t}}$ is the average number of colonies of the two control samples after incubation, 
expressed as $\mathrm{CFU} / \mathrm{ml} ; \lg T_{\mathrm{t}}$ is the average number of colonies of the two control samples immediately after incubation, expressed as $\mathrm{CFU} / \mathrm{ml}$.

\section{CONCLUSIONS}

The results of antimicrobial tests presented a strong antifungal character of the extracts obtained from flowers, leaves and mixed flower leaves. The extracts obtained from the leaf showed antimicrobial activity at a concentration $3 \%$ better than $1 \%$, this being confirmed on both strains. At the same time, it is observed that the sample with $3 \%$ leaf extract (L) has the same influence depending on the strain tested, Trichophyton interdigitale and Epidermophyton floccosum. At the same time, it is highlighted that the entire antifungal character is due to the extracts, and not to the paraffin oil, which does not inhibit the degree of cell viability.

\section{Acknowledgements}

This work was supported by a grant of the Romanian Ministry of Research and Innovation, CCCDI - UEFISCDI, project number PN-III-P1-1.2-PCCDI-20170878/NR. 55PCCDI/2018, within PNCDI III.

\section{REFERENCES}

Boucher, M.-A. et al. (2017), "Anti-Inflammatory, Antioxidant, Antibiotic, and Cytotoxic Activities of Tanacetum vulgare L. Essential Oil and Its Constituents", Medicines, 4(34), https://doi.org/10.3390/medicines4020034.

Garg, J. et. al (2009), "Rapid detection of dermatophytes from skin and hair", BMC Res Notes, https://doi.org/10.1186/1756-0500-2-60.

Grumbt, M. et al. (2013), "Keratin degradation by dermatophytes relies on cysteine dioxygenase and a sulfite efflux pump", J. Invest. Dermatol., 133(6), 1550-1555, https://doi.org/10.1038/jid.2013.41.

Gueho, E. et al. (2015), "Existence of ornamentations on macroconidia and hyphae of Epidermophyton floccosum", Annales de l'Institut Pasteur / Microbiologie, 136(2), Supplement B, 195-203, https://doi.org/10.1016/S0769-2609(85)80044-2.

Jung, S. et al. (2009), "Epidermophyton fungal keratitis following laser-assisted subepithelial keratectomy", Journal of Cataract \& Refractive Surgery, 35(12), 2157-2160, https://doi.org/10.1016/j.jcrs.2009.06.035.

Kumar, V. et al. (2016), "Chemical composition and antibacterial activity of essential oils of Tanacetum", Int. J. Cuur. Microbial. Appl. Sci., 5, 836-884, https://doi.org/10.20546/ijcmas.2016.510.091.

Kupsch, C. et al. (2016), "The agony of choice in dermatophyte diagnostics-performance of different molecular tests and culture in the detection of Trichophyton rubrum and Trichophyton interdigitale", Clinical Microbiology and Infection, 22(8), https://doi.org/10.1016/j.cmi.2016.05.015.

Marian, E. et al. (2013), "Evaluation of antimicrobial activity of some types of inclusion complexes of Erythromycin with $\beta$-cyclodextrin on Staphylococcus aureus", Farmacia, 61(3), 518-525.

Muresan, M.L. (2015), "Antimicrobial effects of the ethanolic extracts and essential oils of Tanacetum vulgare L. from Romania", Food Technol., 19, 75-80, https://doi.org/10.1515/aucft-2015-0016.

Ulukanli, Z. et al. (2017), "Essential oil constituents of Tanacetum: Antimicrobial and phytotoxic activities", J. Food Qual., https://doi.org/10.1155/2017/6214896.

Wisselink, G.J. et al. (2011), "Trapped in keratin; a comparison of dermatophyte detection in nail, skin and hair samples directly from clinical samples using culture and real-time PCR", Journal of Microbiological Methods, 85(1), 62-66, https://doi.org/10.1016/j.mimet.2011.01.023. 